\title{
Donde lo verá el que lo leyere y lo oirá el que lo escuchara leer: sobre el lenguaje metadramático de los títeres de maese Pedro
}

\author{
Eduardo Olid Guerrero*
}

La representación de los títeres de Ginés de Pasamonte en su retablo (final del capítulo 25 y capítulo 26 de la Segunda parte del ingenioso caballero Don Quixote de la Mancha) ofrece una imagen cervantina de la difusión oral y teatral del relato épico según la interpretación de la picaresca española de la época, y en este sentido es un microcosmos que refleja el macromundo de la novela de Cervantes ${ }^{1}$. Este espejo metatextual es un mise en abîme de la línea argumental de toda la novela, lo que significa el texto impreso, y de su carácter eminentemente dramático, lo que significa la manipulación de dicho texto. En la puesta en escena de esas lecturas tenemos el género novelístico o proto-novelístico que inicia Cervantes, y que parte de una reflexión sobre el hecho teatral en toda su concepción. En sus escenas narrativas se incluyen la escenografía, el vestuario, los efectos visuales y acústicos, hasta la interpretación y recepción de la obra por parte del espectador crítico y el público,

* Muhlenberg College.

1. Conocida y aceptada también aquí es la analogía estructural entre este episodio y la estructura del resto de la novela que estableció George Haley en su análisis, y donde ofrece resultados tan clarificadores como el paralelismo Cide/Cervantes y Trujamán/maese Pedro en la función de intermediario, y sobre la hibridez genérica de estas páginas: «el retablo es, a la vez, acción narrativa y representación dramática» (p. 275). Sin embargo, si bien mis conclusiones son deudoras del análisis de Haley, difieren en la supuesta intencionalidad instructora de Cervantes para con un supuesto lector ideal ofrecida en su ensayo: «En la interpretación de los títeres Don Quijote se encuentra cara a cara con la ficción presentada como historia. Reacciona, porque es un loco. Pero el lector sabe a qué atenerse, o al menos lo sabrá, cuando Cervantes haya terminado de aleccionarle. Y la función del retablo le recuerda este hecho una vez más, pero ahora con una analogía que es aplicable al resto de la novela en su totalidad. [...] En esto se parece al lector que Cervantes tenía in mente al escribir su historia: un lector discreto, que aprende a ser avisado por medio de la experiencia, y para el que la intervención de Don Quijote en los títeres es un mal ejemplo que hay que evitar» (p. 286). Como espero demostrar en este trabajo, la ejemplaridad cervantina parecer ser menos didáctica y más compleja en su interpretación. 
cómo sucede con la información de bastidores que ofrece el capítulo $27^{2}$. En el Quijote se ve lo que se lee, se lee lo que no se puede ver pero otros ven, se lee como otros oyen lo que se lee y, como ocurre en el retablo, se lee lo que otros oyen y ven cómo se (re)presenta. En estos capítulos Cervantes deja claro que debemos cambiar nuestro rol de lectores por el de espectadores. En las siguientes páginas me propongo mostrar las diversas características del lenguaje (meta) teatral del retablo de maese Pedro en tanto escenificación de una tradición oral a través del lenguaje dramático y mudo de las marionetas y el discurso declamado por el trujamán que las describe. Como consecuencia de esta (re)presentación tenemos, por un lado, la acogida e interpretación de don Quijote como oyente crítico de una lectura dramática de esa tradición de juglares y, por otro, su reacción coherente con su historia de lector aislado y silencioso. El retablo de maese Pedro se convierte en ejemplo de la lectura pública común de la época. Es el único escenario «real» del Quijote (a diferencia de escenarios no declarados pero con intensa fuerza dramática como por ejemplo las ventas, o el entorno de las bodas de Camacho). Es decir, ante el retablo de maese Pedro se da la única representación en la novela donde todos los personajes, lector incluido, son conscientes de que van a presenciar un hecho ficcional, y no una escenificación dramática encubierta como sucede en muchos otros casos, sobre todo, de la segunda parte de la novela. De este modo, en este espectáculo veremos si la reacción del más importante crítico del hecho ficcional de los títeres de Ginés de Pasamonte, que es don Quijote, es la de un espectador o la de un lector ideal y/o implícito. Como nos recordara Daniel Eisenberg, el romance era una canción, pero una que contenía historia (p. 182). Por tanto, el caballero andante sufre una crisis cuando se plantea la validez de esa historia, sencillamente porque haciéndolo se está planteando su propia existencia. Además don Quijote exterioriza con su reacción el enfrentamiento que durante toda la obra se presenta entre el romance y los libros de caballerías por un lado, y las nuevas formas literarias que venían a suplantarles, destacando la supremacía del teatro de la nueva comedia y lo que se llamará, muchos años después, novela.

En esta línea de reflexión sobre el lenguaje literario del texto de Cervantes, tenemos la solución al conflicto entre la lectura oral, recitada, de la representación del texto teatral del retablo, y la nueva lectura silenciosa que será propia de la novela y de los libros leídos por don Quijote. Podríamos entonces plantear la hipotética paradoja de que don Quijote es un personaje de naturaleza oral de raíz en la épica y en los romances, inmerso en un mundo

2. El escritor de Alcalá, a través de los diálogos de sus personajes, nos ofrece una teoría del teatro en forma metaficcional, y que tienen su origen preceptivo en muy diversas formas de dramaturgia (desde la tradición clásica, la commedia dell' arte o la comedia nueva de Lope). La paradoja cervantina inaugura y construye el género aislado y personal del mundo de la novela, tan propio de su primer lector que es el propio don Quijote, desmontando toda una serie de tradiciones literarias con base en la lectura y el espectáculo colectivo. Esta construcción de una nueva forma de expresión se consigue a través de la hibridez de dos géneros, el drama, incluido el romance como espectáculos orales, y la propia novela moderna que se presenta en su proceso de formación. 
libresco que asume y deconstruye todo tipo de géneros literarios anteriores a Cervantes. Don Quijote pretende una lectura uniforme, histórica y verdadera, en ella no tiene cabida una representación y escenificación libre del romance, puesto que el grado de historicidad de éste es precisamente lo que según el hidalgo lo define. La lectura que don Quijote acaba imponiendo es de esta forma la misma lectura silenciosa que le llevó a su locura o enfermedad.

Tras el planteamiento de nuestro objetivo podemos ya adentrarnos en esa taberna donde está a punto de comenzar el espectáculo: “"Operibus credite, et non verbis", y manos a la labor, que se hace tarde, y tenemos mucho que hacer y que decir y que mostrar» (p. 845). Maese Pedro anticipa con su disfraz un nuevo rol en la historia del caballero andante, viene del pasado, del otro libro, para adentrarse en éste y aprovechar su experiencia previa con el caballero. Ginés es un personaje que la línea narrativa hábilmente oculta para sólo desenmascarar cuando se agota el recurso del suspense en la acción. Por eso sólo más tarde, en la segura explicación del narrador en el siguiente capítulo, comprenderemos que el que fuera preso de galeras ha dejado la palabra escrita de su autobiografía por el beneficio seguro del teatro de marionetas y de la palabra hecha, dicha y mostrada. Gracias a la nueva identidad de Ginés al de la Triste Figura se le ofrece el privilegio no solo de asistir al disfrute en vivo y en colectivo de una escena sacada de la épica caballeresca, sino de presenciar los preparativos y la tramoya del espectáculo:

\begin{abstract}
y vieron donde ya estaba el retablo puesto y descubierto, lleno por todas partes de candelillas de cera encendidas que le hacían vistoso y resplandeciente. En llegando se metió maese Pedro dentro dél, [...] y fuera se puso un muchacho, criado del maese Pedro, para servir de intérprete y declarador de los misterios del tal retablo: tenía una varilla en la mano, con que señalaban las figuras que salían. (p. 845)
\end{abstract}

A través de las descripciones metateatrales del capítulo 25 se encuadra la escena del retablo del capítulo 26. Los preámbulos al espectáculo son los mismos primeros instantes que anticipan el misterio del teatro para los espectadores dentro y fuera del Quijote: «Puestos, pues, todos cuantos había en la venta, y algunos en pie, frontero del retablo, y acomodados don Quijote, Sancho, el paje y el primo en los mejores lugares, el trujamán comenzó a decir lo que oirá y verá el que le oyere o viere el capítulo siguiente» (p. 846) ${ }^{3}$. Resulta sintomático que el final del capítulo 25 de esta segunda parte del Quijote acabe con un personaje en una posición de suspense. Recuerda la misma estrategia narrativa que usara Cervantes para dejar en el aire al lector entre los capítulos 8 y 9 correspondientes a la primera y segunda parte del primer libro ${ }^{4}$.

3. Cito el texto de Cervantes por número de página correspondiente a la edición de Francisco Rico. Cervantes, Miguel de, El ingenioso hidalgo don Quijote de la Mancha, Francisco Rico (ed.), Barcelona, Crítica, 1998.

4. Como bien recordamos, allí tenemos a don Quijote y al vizcaíno con las espadas suspendidas en el aire y a toda una serie de personajes que junto con el lector observan expectantes la resolución 
Oralidad y escritura, lectura pública y lectura silenciosa. James Iffland asocia al hidalgo tanto con la nueva cultura tipográfica como con la lectura en silencio, es una reductio ab absurdum del abuso de esa tecnología naciente $^{5}$ : «Solo, escondido en su biblioteca, Quijano lee durante períodos de hasta cuarenta y ocho horas seguidas, según su sobrina. Dentro de un contexto de lectura en grupo tales megadosis de ficción habrían sido imposibles» (p. 626). Alonso Quijano es el primer, y más famoso, adicto a la «galaxia Gutemberg» documentado. Como resultado, sufre según Iffland de «destribalización»:

aflojamiento de los lazos colectivos que comenzó a producirse cuando el proceso de comunicación ya no implicaba reunirse con otros para escuchar hablar a alguien. Quijano se presenta claramente como una víctima temprana de este síndrome nuevo, siendo una persona cuya forma de consumir textos literarios - estimulado por la nueva tecnología - lo ha «enajenado» o «alienado» (eso es, convertido en otro). (p. 626)

Por suerte para nosotros este «efecto secundario» resulta en la creación de un «alienígena» llegado de esa «galaxia Gutenberg» llamado don Quijote. Una vez que sabemos cuál es el pronóstico, podemos entender las palabras del trujamán: «lo que oirá y verá el que lo oyere o viere» (p. 846). La lectura colectiva es asumida como paralela a la lectura aislada, no son excluyentes, y como siempre la mesura y el buen sentido común pueden con todos los vicios, como Cervantes parece recetar. Margit Frenk recoge el testigo del profesor Iffland y se detiene a pormenorizar los instantes del Quijote donde se realiza una lectura colectiva o muda para concluir: «Cervantes, que leía en silencio, parece jugar con la idea de que también su Quijote podría ser leído oralmente» (p. 28) .

de la escena. Cervantes aprovecha este momento para reflexionar sobre la acogida del texto ficcional a través de un lenguaje autorreflexivo. Es decir, el de Alcalá expone en el Quijote los problemas de la escritura por entregas y la autoría del texto y el origen del propio Quijote desde y para un lector individual. Ya Michel Moner veía toda una serie de paralelismos en la forma de narrar oral de Cervantes en los dos libros del Quijote: «La mise en oeuvre du récit cervantin, telle qu'on peut l'observer dans les premières pages du Don Quichotte de 1605, coïncide sur bien des points avec la performance du truchement de Maese Pedro, c'est-à-dire, en définitive, avec le récit oral —ou tout au moins donné pour tel—d'un conteur professionnel» (p. 104).

5. Anota James Iffland: «Muchos eruditos han estudiado los modos en que la tecnología estimuló la lectura solitaria y silenciosa, entre ellos Walter Ong en su excelente Orality and Literacy: The Technologizing of the Word: "La tipografía era [...] un factor principal en el desarrollo en el sentido de la privacidad o intimidad que marca la sociedad moderna. Produjo libros más pequeños y más portátiles que los que eran comunes en la cultura del manuscrito, preparando el terreno psicológicamente para la lectura solitaria en un tranquilo rincón, y con el tiempo, para la lectura completamente silenciosa"» (p. 625).

6. Con multitud de ejemplos esta investigadora resume: «En las dos partes del Quijote el verbo leer, cuando aparece sin mayores especificaciones, normalmente se aplica a la lectura en silencio. Cuando Cervantes quiere decir leer pronunciando, el verbo va (o ha ido poco antes) acompañado de una fórmula que hace explícita la oralidad de la lectura» (Frenk, p. 76). Esto tiene relación con la conocida vocación dramatúrgica frustrada de Cervantes y sus repetidos intentos de competir con Lope para llegar al público teatral. Pero también tiene consecuencias menos personales ya que Miguel es, con Don Quijote, escritor y dramaturgo y elabora un texto que puede ser leído por unos, con el ejemplo 
En el retablo de maese Pedro la perspectiva adquiere otro matiz más: de la digresión sobre la palabra escrita al uso de la voz teatral y su capacidad para manipular una audiencia. Pasamos pues de un lenguaje metaliterario a un lenguaje metadramático. Una posición metadramática que conecta al intérprete juglaresco con el tablado de marionetas mediante una varilla que con su efecto hipnótico introduce al espectador en el escenario. Pasamos así de las armas expectantes del primer libro del Quijote a una imagen visual de la épica que se escribe para un lector. Por la boca abierta del trujamán, el juglar que canta para un público, en una imagen congelada, entramos al capítulo 26: «Callaron todos, tirios y troyanos» (p. 846).

La Eneida comienza este apasionante capítulo del Quijote. Como ya viera Arturo Marasso siguiendo a Casiano Pellicer, al aceptar el añadido de las palabras «Tirios y Troyanos» a la cita de Virgilio, Cervantes desvela su fuente primaria: la traducción del libro II de La Eneida de Hernández de Velasco (p. 100). Lo que cita Cervantes es así esta versión de La Eneida y no el texto original de Virgilio. La inclusión del contexto de la guerra de Troya no es tampoco gratuito pues conecta con el héroe griego Néstor que aparecerá inserto en una serie de exhortaciones del trujamán que maese Pedro interrumpe. Podemos decir que Troya (don Quijote) entra en Troya (retablo). Este uso de la tradición para transformarla, reciclarla y ofrecerla de nuevo como fuente es uno de los ejes estructurales de este capítulo y por ende de toda la novela del Quijote.

El retablo de maese Pedro representa la historia de Gaiferos y Melisendra según la versión oral que, de acuerdo con Samuel Armistead, Cervantes conoce de «una variante de la "vulgata" recogida en pliegos y cancioneros» («Gaiferos», p. 5) ${ }^{7}$. Por tanto el manco de Lepanto utiliza una variante como en el caso de la cita de Virgilio. El caballero en el anterior capítulo ha preguntado al mesonero por el tal maese Pedro a quien con tanta entusiasmo ha recibido y oye: «Este es un famoso titiritero, que ha muchos días que anda por esta Mancha de Aragón enseñando un retablo de la libertad de Melisendra, dada por el famoso Don Gaiferos, que es una de las mejores y más bien representadas historias que de muchos años a esta parte en este reino se han visto» $(\text { p. } 840)^{8}$. El problema es que esta «representada historia» es una variante más

citado de la desmesura de Alonso Quijano y, al mismo tiempo, presenciado por el que lo escuchara leer: «Nuestra obra está repleta de ejemplos de las distintas maneras en que este acto puede ser realizado y por quiénes [...]. También se ven ejemplos de la lectura oral colectiva, tanto entre gente capaz de leer como entre grupos mixtos y analfabetos [...]. Este grupo que está forzado a escuchar leer a otro aparece a menudo, comenzando por supuesto con Sancho Panza y pasando no solo por el ventero, Maritornes y los segadores sino también por la mismísima Dulcinea» (Iffland, p. 633). Cervantes es sensible a ambos tipos de espectadores porque conoce las limitaciones lectoras de la España que le tocó vivir, y por eso su historia está escrita «para universal entretenimiento de las gentes» y con tanta claridad que «los niños la manosean, los hombres la entienden y los viejos la celebran» (p. 647).

7. Desde la crítica romancística se nos advierte que: «El romance de Gaiferos ha sobrevivido hasta nuestros días en diversas áreas del mundo hispánico y su estudio resulta indispensable para un conocimiento cabal del relato que evoca Cervantes en el retablo de maese Pedro» (Armistead, «Gaiferos», p. 4).

8. Esta reacción del ventero se entiende si sabemos que «La doctrina oficial eclesiástica fulminaba contra los juglares, colocándolos, en un principio, al mismo nivel de las prostitutas y de los delincuen- 
del romance que maese Pedro conoce. Don Quijote no está asistiendo a la promesa de relato adaptado al pie de la letra del original que sin duda conocía, sino a una de las múltiples variedades que producía la tradición oral.

Es más, lo interesante es que el mismo trujamán insinúa esta ahistoricidad cuando con auténtica expectación después de la estruendosa presentación del retablo afirma: «Esta verdadera historia que aquí a vuesas mercedes se representa es sacada al pie de la letra de los romances y de las corónicas francesas que andan en bocas de las gentes» (p. 846). Entendemos que tanto la versión manuscrita como la versión o versiones orales son conocidas por un gran público. En realidad el trujamán, y con él Cervantes, nos está engañando con una ironía verbal que indica que su pretendida intención de veracidad histórica resulta imposible, pues está basada en diferentes versiones de múltiples fuentes, escritas y orales. El declarador actúa como un juglar que puede y debe cambiar mediante la improvisación su propia interpretación de la historia. Su función es «leer» al público para conseguir su aplauso y con ello colmar el afán materialista de maese Pedro. El resultado es, en definitiva, una representación fiel de la variante oral con la que se habría familiarizado Ginés de Pasamonte ${ }^{9}$. El pícaro, autor anónimo que escribía su autobiografía a tiempo real, que recibió bautismos del tipo «Ginesillo de Parapilla» por parte de un hombre de papel sacado de los libros de caballerías, se ha convertido en todo un maese, un dramaturgo heredero de la tradición oral que da su versión de un romance popular ${ }^{10}$. Parentéticamente y como veremos, a estas alturas ese hombre de papel tampoco es el mismo que en 1605 se lanzó a buscar aventuras por los campos de la Mancha.

Esta técnica juglaresca, o tropelía del hacer como si esta escenificación que va a presentarse fuese real, siendo su origen: 1) un texto cronístico que maese Pedro y el trujamán no han leído, y 2) una versión que habrían oído cantar o visto representar, permite que el espectador y el lector del retablo acepten el juego ficcional. La posible veracidad del espectáculo satisface sobre todo al espectador común de la época que conoce el o los romances de Gaiferos; pero también a espectadores como don Quijote, que buscan una experiencia catártica en la mera escenificación de una historia que ya conocen y sobre la que no esperan variantes. Sin duda el trujamán habría sido avisado por maese

tes. Sin embargo la realidad cotidiana difería de tan abstractos e infamantes legalismos. [...] Y se le solía recompensar a manos abiertas: dineros, víveres ... e incluso casa y heredades. Ante tal entusiasmo había que limitar legalmente la generosidad de las recompensas» (Armistead, «Juglares», p. 804).

9. La etimología que ofrece Dominique Reyre sobre estos nombres resulta reveladora: Pasamonte, Ginés de: «de pasar, traverser et monte, bois ou montagne. Ce nom est peut-être l'équivalent du français Tranche-Montagne (1) qui apparut au XIV siècle avec le sens de "Pasamontes" avant de désigner un fanfaron qui sa vente d'exploits extraordinaires (seul sens aujourd'hui conservé)» y añade: «Par le choix de ce nom, Cervantes précipite le monde des héros des romans de chevalerie dans celui de la gueuserie des bandits.» Para Pedro (Maese) dice: «donne à ce titre un sens figuré; il signifie: passé maître dans l'art de mentir, de voler» (p. 116).

10. Ver Clark Colahan, Parodic... para una interpretación hidalgo-pícaro por parte de Ginés en el uso de la preposición «de» como indicador de hidalguía. Resulta extraño que este crítico haya pasado por alto el nombre de Miguel de Cervantes, ¿pícaro o hidalgo? 
Pedro, como él mismo se informaba para su espectáculo del mono adivino, sobre quién es el excepcional asistente al retablo ese día y el asiento privilegiado que tiene en la representación.

Expresiones como «vean vuesas mercedes» o «y aquel personaje que allí asoma» (p. 847) constituyen la forma incesante del declarador de apuntar verbalmente a la escena de títeres en una técnica de auténtico ilusionista que, con su varilla y su voz, conduce nuestra mirada de espectadores/personajes y lectores hacia el movimiento de las marionetas. El intérprete llega a reconocer la poligénesis de la historia al hablar precisamente de los coscorrones apócrifos de Carlomagno a Gaiferos: «y aun hay autores que dicen que se los dio» (p. 847), cuando el único autor que dice «que se los dio» sería maese Pedro. De nuevo Armistead nos aporta los datos desde la tradición del romance y sus variantes: El hecho de que Gaiferos a continuación tira el tablero: «el cual ya ven cómo arroja» (p. 847) no coincide tampoco con la versión del romance escrito pero sí con otras versiones orales («Gaiferos», pp. 4-6 y Judeo-Spanish Ballads, 74) ${ }^{11}$; al igual que ocurre con el descenso de Melisenda (Melisendra sería una transformación modernizada), que en el romance impreso se limita a bajar las escaleras y en el retablo se tira por la ventana, versión también documentada en romances sefardíes o portugueses (Judeo-Spanish Ballads, pp. 74-76 $)^{12}$. Roldán es asimismo tío de Gaiferos y no primo como la variante oral del retablo recogida en otras muestras indica (Judeo-Spanish Ballads, p. 41 n. $^{\circ}$ 26). Pero además el trujamán también crea de modo apócrifo, para alimentar el apetito de un público más interesado en el lirismo que en la heroicidad de la narración: «Miren también un nuevo caso que ahora sucede, quizá no visto jamás. ¿No veen aquel moro que callandico y pasito a paso, puesto el dedo en la boca, se llega por las espaldas de Melisendra? Pues miren cómo le da un beso en mitad de los labios, y la priesa que ella se da a escupir y a limpiárselos [...]» (p. 847). Con ese truco de la novedad, de la creación inesperada de una supuesta improvisación (pues maese Pedro tendría que mover las marionetas acorde con un guión preestablecido), el declamador consigue satisfacer al espectador actual del siglo XVII que sabe de las transformaciones orales de los romances, fijándose en contenidos sentimentales, eróticos o sexuales, o incluso de las versiones escritas que emplean la sátira (pensemos en Quevedo). Otros ejemplos de inventiva original del retablo son: el detalle de que Melisendra se engancha dramáticamente el fadellín al

11. Armistead rastrea el origen de las variantes orales de Gaiferos, entre las que se encuentra la que ofrece Cervantes: «Such widely distributed variant readings as these strongly suggest that the modern tradition must depend on an early prototype (or prototypes) which differed in several, rather minor details from Asentado está Gaiferos, the only extensive version that was to be consecrated in print. As Menéndez Pidal has shown, such a supposition can be confirmed by contemporary non-romancistic evidence and in no less a source than Maese Pedro's Retablo (Don Quijote, II, chap. XXVI; Romancero Hispánico, I, p. 288)» (Judeo-Spanish Ballads, p. 74).

12. El eminente medievalista concluye que: «Both in Gaiferos' throwing down his tablero and in Melisendra's dramatic descent, the Retablo shows us that Asentado embodies, for whatever reason, an attenuated, less dramatic reading, while Cervantes and several branches of the modern tradition share a more sensational view of the events» (Armistead Judeo-Spanish Ballads, p. 77). 
saltar; la disputa de la espada Durindana, o los ya mencionados golpes de Carlomagno con el cetro.

Por otro lado, el declamador también sabe aún contentar al oyente que pide una mínima fidelidad histórica en la adaptación. El problema real surge cuando el trujamán improvisa dando opiniones valorativas que no vienen al caso. Valoraciones que podían servir para instigar prejuicios de cierto público a quien el juglar considerara apropiado lanzar este tipo de consignas, pero que ante un espectador crítico que valora su actuación a tiempo real, y que espera una lectura lineal, no funciona: «-Niño, niño — dijo con voz alta a esta sazón don Quijote-, seguid vuestra historia línea recta y no os metáis en las curvas o transversales, que para sacar una verdad en limpio menester son muchas pruebas y repruebas» (p. 848). Don Quijote habla «en voz alta» con una clara intención de evitar el prejuicio lanzado contra los moros por el trujamán hacia una audiencia que si no fuera por nuestro caballero lo habría aceptado. Este dato concede una función al declarador como agente manipulador de un discurso actual sobre la expulsión de los moriscos. Algo que seguramente el intérprete acostumbraría hacer a menudo y que maese Pedro aprovecha para criticárselo a la sazón del comentario de don Quijote: «Muchacho, no te metas en dibujos, sino haz lo que ese señor te manda, que será lo mas acertado: sigue tu canto llano y no te metas en contrapuntos, que se suelen pasar de sotiles» (p. 849), para poco después, y sin poder sufrir la afectación del trujamán, volverle a interrumpir para recordarle que: «-Llaneza, muchacho, no te encumbres, que toda afectación es mala» (p. 849). Este control de la palabra como instrumento de poder sobre el vulgo se convierte en asunto serio y en el tema principal del retablo. Así son pertinentes aquí las palabras de Michel Moner:

Il n'est que trop évident, en effet, que les conteurs cervantins ne sont pas seulement des porteurs de récit, qui n'auraient d'autre fonction - comme les créatures hybrides des Mille et une nuits - que de raconter des histoires pour le plus grand plaisir de leurs auditeurs: la plupart sont solidement ancrés dans la société de leur temps et, par là même, révélateurs des vives tensions idéologiques. (p. 12)

Cervantes pone sobre la mesa o retablo las cuestiones que más le importan de la sociedad en que vive, no para ofrecer soluciones mágicas sino para plantear y de este modo intentar depurar los conflictos que le rodean. Su protagonista busca un mundo perfecto que por ser literal no existe. El caballero se preocupa demasiado por que se le ofrezca una lectura literal del retablo e insiste en esa ruptura de la cuarta pared teatral. Apoyado en la seguridad de su competencia lectora exclama ${ }^{13}$ : «—iEso no! —dijo a esa sazón don

13. Coincidimos con Cory Reed: «He corrects others - their languages and pronunciation, their ability to reason, to formulate arguments, and to tell stories. He does not do this maliciously; simply perceives inaccuracy in those around him. His desire to correct others is a desire for precision» (p. 740). 
Quijote. En esto de las campanas anda muy impropio maese Pedro, porque entre moros no se usan campanas, sino atabales y un género de dulzainas que parecen nuestras chirimías; y esto de sonar campanas en Sansueña sin duda que es gran disparate. Lo cual oído por maese Pedro, cesó el tocar y dijo:» (pp. 849-850). Dejemos al titiritero por decir lo que dijo para aclarar que don Quijote y maese Pedro interrumpen el discurso oral metaficcional del trujamán a costa de la representación, del entretenimiento. "They call attention to the business of telling at the expense of the told» (Gaylord, p. 124). De nuevo el discurso, el cómo decir es el centro de toda la escenificación.

Entre la visión y representación de las marionetas y el lenguaje revelador de los misterios escénicos del trujamán, intuimos una estructura narrativa sugestiva, esto es, una manera de hablar y representar el teatro dentro de una novela eminentemente dramática ${ }^{14}$. El primer paso en la definición crítica de este tipo de palimpsesto lo dio Lionel Abel: «I have defined metatheatre as resting on two bases: [1] the world is a stage and [2] life is a dream» (p. 83). Según esta definición el caso que nos ocupa del retablo de maese Pedro se identifica rápidamente con «la común idea de nuestro Siglo de Oro de la vida humana como representación» (Diez Borque, p. 120). Si filosóficamente este concepto es muy productivo, como ya lo demostrara Américo Castro: «Cervantes aprovecha los títeres para insistir una vez más sobre la distinción entre lo divino y lo humano» (p. 506). Para mi propósito esta lectura no es tan útil ya que se relaciona con una interpretación simbólica del texto. Con el término «metadrama» concreta Richard Hornby un poco más: «Briefly, metadrama can be defined as drama about drama; it occurs whenever the subject of a play turns out to be, in some sense, drama itself» (p. 31). Aunque estructural y meramente descriptiva, su clasificación de los cinco tipos de metadrama tiene un uso de más alcance metodológico. Así, en el retablo, es fácil ver una correspondencia con cada una de estas variantes: En primer lugar, la obra dentro de la obra: el retablo dentro del Quijote que seguimos como referencia estructural. Como segundo tipo: la ceremonia dentro de la obra, el teatro ambulante de marionetas y su recepción popular: un carnaval en tiempo de cuaresma como un oasis libre de la censura ${ }^{15}$. En tercer lugar tenemos el rol dentro del rol: la decisión del personaje de cambiar su papel de forma voluntaria, caso de Quijano convirtiéndose en don Quijote, o no tan voluntaria, caso de Ginés que elige ser

14. Sobre el Quijote como texto dramático y su teatralidad ver: Ramos Escobar y SyversonStirk. A propósito del teatro dentro del teatro en Cervantes: Diez Borque. Y Martín Morán sobre los escenarios teatrales en el Quijote.

15. La ceremonia como dice John Varey corresponde temáticamente al tiempo de maese Pedro que es la cuaresma, «la cuaresma es el verdadero carnaval del titiritero» (p. 242). Por tanto un tema religioso predominante que maese Pedro decide obviar por un tema secular más apto a la parodia si quería evitar problemas con la inquisición. A lo que debemos añadir el apunte de Heraldo Falconi: «El motivo de la historia del rescate de Melisendra es sacado de las entrañas mismas del imaginario social y popular europeo, el tema recurrente evocado por aquel Mester de Juglaría — difusor de los valores carnavalescos alrededor de todo el año-》 (p. 7). Por otro lado, el nombre de Ginés establece otro nexo con el teatro, según Alfred Rodríguez, San Ginés es patrón de actores y emblema del barroco (p. 440). 
maese Pedro para no ser reconocido por su pasado e identificado por la justicia. La cuarta variante son las referencias literarias y a la vida real: el uso de los romances y sus variedades orales para producir placer y beneficio económico con un espíritu acorde con la realidad actual barroca. Para ejemplificar esta cuarta variedad podemos ahora sí dejar continuar la línea narrativa y con ella a maese Pedro, que contesta a la insistencia del caballero:

No mire vuestra merced en niñerías, señor don Quijote, ni quiera llevar las cosas tan por el cabo, que no se le halle. ¿No se representan por ahí casi de ordinario mil comedias llenas de mil impropiedades y disparates, y con todo eso, corren felicísimamente su carrera y se escuchan no solo con aplauso, sino con admiración y todo? (p. 850)

La quinta y última posibilidad metadramática es la autorreflexión, el Quijote del Quijote. Si bien no se trata en el retablo de la elaboración del libro de Cervantes dentro del propio libro como en otros episodios, Carlos Arturo Arboleda, a propósito del pasaje anterior, considera el retablo como «una obra teatral en la que se comentan elementos también de carácter teatral. Estos elementos traídos aquí por Cervantes están en el fondo cuestionando todo el teatro de su época, en especial el carácter "impropio" de muchas de las comedias de Lope» (p. 65). En el trabajo de Frenk no se antepone directamente la actitud de Cervantes a la de Lope, pero sí se ve claramente la postura de cada uno respecto a la publicación de sus textos dramáticos ${ }^{16}$. Para Cervantes sí era importante ver sus obras impresas ya que como sabemos era quizás lo único que podía hacer con ellas. Pero esto explica también que con ello evitaba tener que pasar por el calvario que años después pasó Lope, cuando quiso recoger sus obras para la impresión y no pudo casi reconocerlas. En el retablo de Melisendra se percibe una crítica autorreflexiva desde el texto cervantino a las ideas discriminatorias o «impropias» a propósito de una lectura impresa del teatro, pues incluye las dos al mismo tiempo. Tenemos el lector que por primera vez se convierte en espectador, don Quijote, y al resto de personajes, acostumbrados asistentes a los espectáculos públicos de la época, ya fuesen callejeros, o en tabernas o corrales de comedias.

Mediante los preámbulos, las interrupciones y las particulares críticas al estreno una vez finalizado, Cervantes ofrece la explicación y la descripción del entramado de la experiencia teatral, nos muestra cómo se monta este andamio y truco narrativo delante de su nuevo lector ${ }^{17}$. En este sentido

16. Apunta Margit Frenk: «A Lope no le interesaba mucho el hecho de que los editores se interesaran por publicar sus comedias, trasladándolas de su medio natural e idóneo a otro radicalmente diferente: del espectáculo colectivo en un teatro al libro leído por una persona en soledad y en silencio. Lo afirmó expresamente: "no las escribí con éste ánimo ni para que los oýdos del teatro se trasladaran a [...] los aposentos" [...].» Actitud muy distinta a la de su competidor: «En aquel pasaje de la Adjunta del Parnaso en que Cervantes escribe sobre sus comedias: "yo pienso darlas a la estampa, para que se vea de espacio lo que passa apriessa y se disimula o no se entiende quando las representan"» (p. 79).

17. Apunta María Caterina Ruta: «Es como si asistiéramos a un espectáculo del que nos desvelaran todos los artificios en la más completa conciencia de la ficción escénica» (p. 706). 
es pertinente aquí la otra lectura del efecto metateatral que aporta Patrice Pavis:

Metateatro designa, por otra parte, no un tipo o un sentido de obra, sino una propiedad fundamental de toda comunicación teatral. La «operación meta» del teatro consiste en tomar la escena y todo lo que la constituye - el actor, el decorado, el texto - como objetos metacríticos, es decir ataviados con un signo demostrativo y denegativo («no es un objeto sino una significación del objeto»). (p. 310)

Como tal signo la función de este recurso literario en manos de un personaje es eminentemente comunicativa. El trujamán es el traductor, el intérprete que se sitúa entre maese Pedro emisor y don Quijote receptor, y es el principal destinatario de los comentarios del caballero. Pero el lector contempla además un diálogo más sutil desde el texto hacia su actividad lectora y como espectador de su propia imaginación. Esta es la varilla mágica de Cervantes, su pluma que habla desde el texto sobre el texto. El problema y el logro está en que Cervantes consigue incorporar en un texto narrativo, un metatexto teatral donde lo literario pasa a lo teatral y viceversa. Aquí están presentes las acotaciones de un director escénico: maese Pedro (que no olvidemos es actor disfrazado sin identidad para personajes y lectores hasta el próximo capítulo); y también contamos con la aportación de otro actor, personaje, espectador y crítico llamado don Quijote que acepta la respuesta de maese Pedro a su interrupción con una simple réplica: «-Así es la verdad» (p. 850).

No respetando por fin los deseos de su más ferviente y entregado espectador sobre la fidelidad de la banda sonora del retablo, prosiguió el muchacho describiendo una escena que se llena en su mismo clímax de todos los sonidos y ruidos que maese Pedro tiene a mano ${ }^{18}$. La duda que hábilmente impone el trujamán sobre la posibilidad última de volver a tergiversar la historia, esta vez en su mismo clímax y desenlace, se convierte en amenaza para don Quijote, que «viendo y oyendo» (p. 850), se identifica hasta tal punto con los títeres, que entra en su diminuto universo para cumplir con el rol que se le niega permanentemente en todo el libro. Y así, de nuevo «en voz alta», dijo: «No permitiré yo que en mis días y en mi presencia se le haga superchería a tan famoso caballero y a tan atrevido enamorado como Don Gaiferos. ¡Deteneos, mal nacida canalla, no le sigáis ni persigáis; si no, conmigo sois en la batalla!» (p. 850).

Don Quijote experimenta una comunicación con esos títeres mudos del retablo ${ }^{19}$. Estas figurillas están cargadas de un significante y significado

18. Según el professor Armistead: «Indicio de los talentos diversificados de la juglaría medieval es la gran variedad de instrumentos musicales propios de su oficio: entre los de cuerda, figuraban cedra, cítola, vihuela [...]; instrumentos de viento: [...] chirimía, flauta [...]; y de percusión: atambor, atabal y panderete» (p. 805).

19. Es preciso anotar que parte de la crítica cervantina, olvidándose de la principal función comunicativa que ejercen estas figuras de pasta desde el escenario, ha insistido en rastrear con afán detallista cual fue el tipo de títere en que Cervantes se inspiró o tenía en mente cuando elaboró el retablo de 
flotantes en la imaginería colectiva. Ajenas a las fantasías impresas de los libros de caballerías, sirven sin embargo usualmente para sacarlas del papel y llevar esas historias al espectáculo público. Los títeres otorgan esa libertad de reciclaje de géneros y formas de relato orales que a Cervantes le interesa. Con datos de estudios de John Varey, Daniel Keller señala la popularidad de las marionetas sobre todo durante festividades religiosas porque al no ser consideradas como teatro no estaban sujetas a la prohibición de las representaciones, por lo que podían sacar beneficio de su espectáculos durante tales fechas sin la competencia de los actores de carne y hueso (Keller, p. 206). Una situación material ventajosa que sin duda nuestro Ginés valora. La ceremonia metadramática de las marionetas de maese Pedro goza pues de un salvoconducto para actuar en impunidad y sin competencia.

Estas creaciones se alimentan de la tradición oral y de su inventiva: «Probably improvisation and oral transmission were the rule then as now» (Keller, p. 206). Maese Pedro como buen pícaro ha aprendido a leer la vida, como dice don Quijote: «el que lee mucho y anda mucho vee mucho y sabe mucho» (p. 842). El caballero sí ha leído, o su creador y metacreador lo hicieron, y ahora le toca a él vivir en andanzas. El titiritero y su criado-intérprete son portadores de una pequeña ventana de ilusión que para un ser salido de la fantasía de un hidalgo empedernido lector significa, a estas alturas del libro, quizás la última esperanza para justificar su existencia. Después de ver y oír, habiendo ya intentado e insistido en la crítica constructiva sin recibir más que humillaciones físicas y verbales, le toca ahora actuar y destruir: «Y diciendo y haciendo, desenvainó la espada y de un brinco se puso al retablo, y con acerada y nunca vista furia comenzó a llover cuchilladas sobre la titerera morisma, derribando a unos, descabezando a otros, estropeando a este, destrozando a aquel $[\ldots] \gg($ p. 850).

Estas marionetas se convierten en víctimas reales al ser los portadores del signo ficcional: «Les indicateurs de fiction que sont les marionnettes rendent le lecteur sensible à la projection incontrôlée d'un personnage fictif» (Gilles, p. 17). Don Quijote cree que actúa en consecuencia con su destino literal y por eso lee correctamente el otro universo literario que se le propone. No pretende demostrar nada en concreto, pero si de algo entiende es de asuntos caballerescos, y por fin el texto y estos «indicadores de ficción» con o sin hilos le dan la oportunidad de poner en práctica estos conocimientos. El resultado de sus acciones es de gran impacto visual gracias a ese efecto de multiperspectivismo que transmiten los gerundios encadenados. Truco discursivo paralelo al que utiliza Cervantes para describir la diversidad de efectos en las distintas reac-

maese Pedro. Guillermo Díaz-Plaja, por ejemplo, insistió en la relación con los puppies sicilianos. Pero fue John Varey quién tras describir minuciosamente los posibles modelos concluye: «El retablo de Maese Pedro puede que se base en una representación de títeres - de marionetas, de fantoches o de autómatas - que viera Cervantes; pero no es una reproducción fotográfica de tal representación. El Quijote es obra de creación, no de reportaje» (p. 287). Incluso la palabra «títere» como registra Américo Castro no tiene más uso fuera de los caminos itinerantes: «Es muy probable que tal vocablo, lo mismo que el objeto que designaba, tuviese vida sólo popular» (p. 508). 
ciones de los personajes de la escena: «Alborotóse el senado de los oyentes, huyóse el mono, [...] temió el primo, acobardóse el paje, y hasta el mismo Sancho Panza tuvo pavor grandísimo» (p. 851). Todas las posibilidades para explotar el espacio y los actores que lo ocupan son apuntadas. Pero, además Cervantes vaticina las reacciones metateatrales de los personajes e incluye las posibles recepciones de los lectores u oyentes de su historia.

En este punto, creer se convierte en la última acción posible que va dejando la duda en la ilusión de don Quijote. Si antes en el primer libro su obsesión no tenía fisuras y él era el dramaturgo que creaba todo el espectáculo, ahora necesita constatar ante todos su propia existencia de personaje (recordemos el chantaje de don Quijote a Sancho para que creyese su historia de la Cueva de Montesinos a cambio de él creer la de Clavileño). Triunfante anuncia: «-Quisiera tener aquí delante en este punto todos aquellos que no creen ni quieren creer de cuánto provecho sean en el mundo los caballeros andantes» (p. 851). Pero ante la evidencia de sus actos recurre a la fácil y siempre útil excusa de los encantadores: "Ahora acabo de creer - dijo a este punto don Quijote - lo que otras muchas veces he creído: que estos encantadores que me persiguen no hacen sino ponerme las figuras como ellas son delante de los ojos, y luego me las mudan y truecan en las que ellos quieren» (p. 852) ${ }^{20}$. Don Quijote no especifica en qué le mudan los encantadores estas figuras por lo que entendemos que el sujeto de «las» es «figuras» que son mudadas en otras figuras. Todo el universo del caballero está lógicamente habitado de figuras, de títeres. De las marionetas es fácil pasar a los encantadores. De unos indicadores de ficción mudos a una fuerza invisible de la providencia alimentada con el mismo silencio que consumió al hidalgo.

Poco a poco vamos intuyendo hacia dónde se dirige el juego metaficcional de Cervantes. Su lector protagónico literal busca una interpretación catártica fiel y constantemente contrastada con su corpus literario. Esta posición calificada por Michel Foucault como «alienated in analogy» se expone abiertamente como interpretación ingenua del mundo. Pero no es una condición de asociación con la realidad permanente que sirve para tachar simplemente a don Quijote de «loco». Su interpretación del mundo cambia a medida que el libro progresa y eso es lo que leemos. El retablo es un ejemplo del cambio producido en el intercambio comunicativo que experimenta el caballero con la realidad.

Escuchar y oír son dos habilidades del decoro. Oír al emisor es parte del trabajo de discriminación de voces como primera fase que debe realizar el receptor en su papel de destinatario de la comunicación. Una vez asegurada esta función apelativa, el oyente debe pasar a ser receptor y decodificador de

20. En una lectura simbólica, Helena Percas de Ponseti deduce que: «la palabra céntrica a cuyo alrededor gira el simbolismo del retablo es figura [...] Con la palabra figura utilizada para designar a las marionetas, Cervantes evoca gráfica y sensualmente la historia de la humanidad encarnada en los personajes del romancero, pero dándole un cariz burlesco como auto sacramental en manos de un autor-titiritero» (pp. 596-597). 
la información del mensaje transmitido. Don Quijote no sólo es un oyente modelo, sino, y esto es lo más sorprendente en el caso de un hombre supuestamente loco, es un ejemplo de destinatario que no sólo escucha y recibe la información sino que la decodifica, la procesa y la interpreta confirmando el éxito de la comunicación como ningún personaje en toda la novela. Si a esto añadimos la ya notada adversidad de su enfermedad mental, tenemos un interesante caso de interpretación de la realidad ficcional aprehendida en su totalidad para procesarla y rebatirla de modo congruente, atendiendo a códigos de discurso retórico y exposición discriminatoria según el destinatario de la comunicación. En otras palabras, don Quijote sabe sobre qué y a quién dirige sus palabras en todo momento. El problema está en que muy pocos le entienden y cuando lo hacen es para utilizar su propio modelo discursivo de lenguaje elevado para ridiculizarle. El caballero se enfrenta indefenso, como un títere mudo, al complejo universo protonovelesco que (de)construye Cervantes:

\begin{abstract}
The key to the breakdown of don Quijote's literalist model is the idea of complexity. Don Quijote cannot understand the many codes that intersect in the complex system of Cervantes's novel [...] He cannot understand others and they cannot understand him, and this failure to communicate often converts him into an object of ridicule. (Reed, p. 741)
\end{abstract}

El cambio de nivel del registro discursivo es un recurso picaresco que Ginés pone en práctica, como hiciera en el capítulo 22 al ser liberado como galeote por don Quijote. De nuevo cuando oye que el caballero le promete «condenarme a costas» (p. 853), esto es una recompensa económica por el valor de sus figuras destrozadas, declama: «-No esperaba yo menos de la inaudita cristiandad del valeroso don Quijote de la Mancha, verdadero socorredor y amparo de todos los necesitados y menesterosos vagamundos» (p. 853).

Así empieza la tasa y pago de las figuras con Sancho y el ventero como testigos. En la intervención de don Quijote a este cómputo mercantil apreciamos el cambio que su estado mental va experimentando a medida que avanza el segundo libro. Si la cueva de Montesinos sembró ya una gran duda en su mente a través del inconsciente onírico, ahora la realidad le golpea con toda su fuerza de dos modos: Primero, con un proceso de sanchificación que le consume incluso con necesidades que antes no tenía, o rechazaba en su condición de caballero, o cuando la ocasión le presentaba cualquier tipo de relato oral, pero que reacciona ante el interés usurero de Ginés: «y acabe presto maese Pedro, que se hace hora de cenar, y yo tengo ciertos barruntos de hambre» (p. 853). Segundo y al mismo tiempo, la humillación de resignarse a pagar por una ilusión frustrada no le impide tener, junto con un último intento de imponer su mundo de lector sobre la compleja realidad, un cierto tono de desconfianza ante el abuso, más propio de Sancho que del Quijote del primer libro: «y, así, no hay para qué venderme a mí el gato por la liebre, presentándome aquí Melisendra desnarigada, estando la otra, si viene a mano, ahora holgándose en Francia» (p. 854). 
La duda aparece una vez más al final de este capítulo cuando, de forma un tanto patética, don Quijote sugiere durante la cena que pagaría si alguien le confirmase su ilusión: "Y doscientos diera yo ahora en albricias a quien me dijera con certidumbre que la señora doña Melisendra y el señor Don Gaiferos estaban ya en Francia y entre los suyos» (p. 853). Maese Pedro recoge con pícaro interés la imposible oferta si pudiera encontrar a su mono. En suma el universo del Caballero de la Triste Figura lentamente se desmorona en su mente. Empieza a valorar cuestiones de intereses humanos como el hambre o el dinero ajenos a la inmortal condición de los héroes literarios que imita. Un proceso irreversible que acabará con su muerte literaria a manos del Caballero de la Blanca Luna.

A modo de conclusión se puede ya afirmar que la imposición de la lectura silenciosa por don Quijote en el libro que le ha tocado vivir es una muestra de su discurso asumido como personaje ficticio. Es la paradoja del ser ficcional propio de un relato épico oral que reclama su independencia del rol asignado de hidalgo, por el rol elegido de caballero andante en un relato producto de una lectura personal aislada. Maese Pedro es un personaje nacido en la tradición literaria picaresca que también opta por la libertad a la hora de cambiar su rol de personaje de truhán por el de titiritero. De este modo el caballero se convierte en defensor de una interpretación del mundo verosímil e histórica con una base filosófica de valores absolutos, mientras que Ginés se convierte en un dramaturgo que interpreta la realidad a su antojo y que niega la necesaria adecuación de historicidad para con su relato, poniendo como ejemplo la libertad con la que operan las comedias de la época, lo que es asimismo un apunte directo a las comedias lopescas. Maese Pedro se sirve de la tradición oral de los cantares de gesta y los romances, unido al recurso técnico que utiliza el trujamán de las fórmulas memorísticas del juglar, para transformar el relato escrito que conoce don Quijote en una representación dramática que tiene como objetivo influir en una audiencia para conseguir una compensación económica inmediata.

La interpretación crítica de don Quijote, si bien es en un principio la de un espectador ideal por ser un lector de gran competencia literaria, no es, sin embargo, el espectador implícito de los romances orales o el espectador modelo del retablo de Melisendra. La reacción de don Quijote es la de un lector indignado con la falta de veracidad histórica del relato, en tanto esta verosimilitud (re)ordena el complejo caos de la novela-mundo que le ha tocado habitar ${ }^{21}$. No es consciente, como algunos han sugerido (caso de Arboleda y Torrente Ballester), de sus actos en relación a los personajes ficticios que observan la representación, ni en relación a los personajes ficticios que la crean, ni en

21. No voy tan lejos como Mary Malcolm Gaylord para apuntar a una crítica consciente de Cervantes a la historiografía de la época aunque su lectura resulta interesante: «I believe that, in his great novel generally and with the Maese Pedro episode and its textual frames in particular, Cervantes takes on a very real, and often very serious national and cultural historiographic project that have been carried forward with special intensity since the end of the fifteenth century and continued to occupy the Spanish historical imagination into the seventeenth» (p. 127). 
relación a nosotros como espectadores incluidos o asumidos desde el texto ${ }^{22}$. Don Quijote no miente. Si en ese momento don Quijote ratifica su condición de caballero en un mundo ajeno es aquí, ante el retablo de Ginés, cuando don Quijote es don Quijote en ese instante tan sólo en la mente de don Quijote, como «Melisendra es Melisendra y Don Gaiferos Don Gaiferos» sólo en la imaginación del caballero. A propósito anota acertadamente Jose M. ${ }^{a}$ Diez Borque: «La transformación "a lo real" que efectúa don Quijote exige: "es". Frente al parecer de la comedia» (p. 126).

Como personaje salido de los relatos épicos don Quijote es habitante de un mundo complejo lleno de otros mundos que remiten a la realidad histórica de su tiempo, de los mundos de las tradiciones orales y géneros literarios anteriores y contemporáneos, y de esos mundos posibles propios de la novela que la historia del hidalgo contempla y vaticina. Todo esta amalgama, reflejo de la complicada realidad a la que se enfrenta tan pronto como sale de su casa de la Mancha, contrasta con el mundo lineal, directo, fácil y claro que desarrollan los libros de caballerías destinados a una lectura en voz alta ya que su origen era la oralidad de los romances y de los cantares de gesta.

Don Quijote por tanto es un lector solitario de libros de caballerías con una enfermedad interpretativa que aparece por la falta de diálogo, de comunicación de esos mundos posibles de los que hablan los Amadies, o los Roldanes; que aunque monotemáticos, elitistas y demasiado artificiales, no por ello dejan de producir placer y entretenimiento como muchos personajes reconocen en esta «verdadera historia» (p. 846). Nuestro caballero necesita la comunicación de esos mundos convertidos ahora en uno: el de su creación por la falta de un interlocutor a la altura de Alonso Quijano el bueno. Cervantes concede en su palimpséstica estructura narrativa, una relativa autonomía de personaje basada en la variante técnica del metadrama del rol voluntario dentro del rol. El hidalgo sólo disfruta de una única ocasión en toda la novela en que puede crear nombrando (a sí mismo y a Rocinante) en absoluta libertad, sin tener que contrarrestar su arbitrariedad interpretativa con alguien más, y esto, claro está, porque aún está solo en su universo cerrado e incomunicado con el mundo exterior. De ahí la importancia de las distintas salidas, pues las aventuras de don Quijote, su viaje de transformación vital por un sueño no tendrían sentido en la soledad de su biblioteca. Sin embargo, aunque elige cambiar de personaje, no por otro personaje, no por Amadís por ejemplo, sino por un personaje salido de su propia imaginación, y de que, haciéndolo, pasa de ser un lector pasivo a ser un personaje activo, el problema está en que decide dejar de ser Alonso Quijano, personaje «real» y por ende «complejo», a imitar un personaje de papel, hecho de la materia «simple» del mundo de la

22. «¿Será que hay que creerle? [...] Don Quijote no es una víctima de ningún encantador, sencilla e irónicamente esa es su táctica [...], su objetivo por y para el cual salió de aquel "lugar de la Mancha": buscar aventuras, actuar» (Arboleda, p. 66). Por su parte Torrente Ballester opina que: «Personalmente es la única ocasión en todo el libro, en que cabe preguntarse si don Quijote miente o no» (p. 185). Curiosamente también ve este crítico lo opuesto: «Es la única ocasión en que puede admitirse, no la creencia en la operación encantatoria, pero sí la ilusión momentánea» (p. 185). 
literatura caballeresca. La incomprensión de don Quijote del universo «real» que Alonso Quijano le obliga a vivir desde el momento en que se abren las puertas de su caballeriza, le sirve a Cervantes para poner un interrogante sobre el sentido de su propio mundo.

La razón o la necesidad de Alonso «el bueno», insisto en ello, es la ausencia de comunicación que experimentaba como hidalgo y solitario lector, y le llevan ya como don Quijote a ese incesante diálogo con Sancho Panza. Esta relación entre caballero y escudero es el verdadero motor de todo el relato. Es un coloquio del que el mismo don Quijote se asombra por no ser parte estructural de la línea narrativa del género literario tan reducido y tan irreal que él conoce. El diálogo es el gran descubrimiento de Cervantes que ya heredara de La Celestina. Le permite no solo dar el perfil de los personajes a través de las propias palabras de éste, sino, sobre todo, y aquí está el gran triunfo cervantino, construir un espacio ficcional orgánico donde los lectores somos testigos de la evolución y del crecimiento de la que es posiblemente la más importante historia de amistad que se conoce entre dos hombres.

\section{OBRAS CITADAS}

ABel, Lionel, Metatheatre. A New View of Dramatic Form, New York, Hill and Wang, 1969.

Arboleda, Carlos Arturo, Teoría y formas del metateatro en Cervantes, Salamanca, Universidad de Salamanca, 1991.

ARMiSTEAD, Samuel G, «Juglares», en Diccionario de Literatura Española e Hispanoamericana, Madrid, Alianza Editorial, 1993.

ARMisteAD, Samuel G., Judeo-spanish ballads from oral tradition. IV: Carolingian ballads (3): Gaiferos, Newark/Delaware, Juan de la Cuesta, 2005.

ARmistead, Samuel G., «Gaiferos», en Enciclopedia cervantina, Alcalá de Henares, en prensa.

CASTRO, Américo, «La palabra "títere”», Modern Languages Notes 57.7 (1942), pp. 505510.

Colahan, Clark y Rodríguez, Alfred, «Parodic Alteration of the Picaresque in Cervantes' Ginés de Pasamonte/Ginesillo de Parapilla», Modern Language Review 85.3 (1990), pp. 609-611.

Cervantes, Miguel de, Don Quijote de la Mancha, Francisco Rico (ed.), Barcelona, Crítica, 1998.

Díez Borque, J. M., «Teatro dentro del teatro, novela dentro de la novela en Miguel de Cervantes», Anales Cervantinos, 11 (1981), pp. 113-128.

Diaz-Plaja, Guillermo, «El retablo de maese Pedro», en En torno a Cervantes, Madrid, Eunsa, 1977.

FALCONI, Heraldo, «El retablo de la libertad de Melisendra: Entre hedonismo y ascetismo», Hispanic Culture Review 3.1 (1996), pp. 4-11.

Foucault, Michel, The Order of Things, New York, Vintage, 1994.

FrenK, Margit, Entre la voz y el silencio, Alcalá de Henares, Centro de Estudios Cervantinos, 1997.

GAYLORD, Mary Malcolm, «Pulling Strings with Master Pedro's Puppets: Fiction and History in Don Quixote», Cervantes 18.2 (19989, pp. 117-147. 
GILLES, Annie, Images de la marionnette dans la littérature: textes écrits ou traduits en français de Cervantes a nos jours, Editions Institut International de la Marionnette, Nancy, Presses Universitaires de Nancy, 1993.

Haley, George, «El narrador en don Quijote: El retablo de Maese Pedro», en El Quijote de Cervantes, George Haley (ed. y trad.), Madrid, Taurus, 1989.

HoRnby, Richard, Drama, Metadrama and Perception, Cranbury, NJ, Associated University Press, 1986.

IfFLAND, James, «Don Quijote dentro de la galaxia Guttenberg (reflexiones sobre Cervantes y la cultura tipográfica)», Journal of Hispanic Philology, 14 (1989), pp. 23-41.

Keller, Daniel S., «Historical Notes on Spanish Puppetry», Hispania, 42.2 (1959), pp. 205-209.

Marasso, Arturo, Cervantes. La invención del Quijote, Buenos Aires, Biblioteca Nueva, 1947.

Martín Morán, J. M., «Los escenarios teatrales del Quijote», Anales Cervantinos, XXIV (1986), pp. 27-46.

MENÉNDEZ PIDAL, Ramón, Romancero hispánico (hispano-portugués, americano, y sefardi), 2 vols., Madrid, Espasa-Calpe, 1953.

Moner, Michel, Cervantes conteur: écrits et paroles, Madrid, Casa de Velásquez, 1989.

Pavis, Patrice, Diccionario del teatro. Dramaturgia, estética, semiología, Barcelona, Paidos, 1984.

Percas de Ponsetti, Helena, Cervantes y su concepto del arte. Estudio crítico de algunos. Aspectos y episodios del «Quijote», Madrid, Gredos, 1975.

PereIRA, Óscar, «Teatrum mundi: Cervantes y Calderón», Anales Cervantinos, 27 (1989), pp. 375-392.

RAmos Escobar, José Luis, Que trata de la teatralidad en el Quijote así como de otros sucesos de feliz recordación, Antonio Vilanova (ed.), 4 vols., Barcelona, Promociones y Publicaciones Universitarias, 1992, vol. I, pp. 671-678.

ReYre, Dominique, Dictionnaire des noms des personages du Don Quichotte de Cervantes. Suivi d'un analyse structurale et linguistique, Paris, Editions Hispaniques, 1980.

ReED, Cory A., «Chaotic Quijote: Complexity, Nonlinearity and Perspectivism», Hispania, 77.4 (1994), pp. 738-749.

RodrígueZ, Alfred, «Ginés de Pasamonte/Ginesillo de Parapilla/Maese Pedro: La barroca transformación del pícaro», Romanische Forschungen, 102.4 (1990), pp. 438-442.

RUTA, María Caterina, «La escena del Quijote: apuntes de un lector-espectador», en Actas del X Congreso de la Asociación Internacional de Hispanistas, Barcelona, PPU, 1992, pp. 703-711.

Syverson-Stork, Jill, Theatrical Aspects of the Novel: A Study of Don Quijote, Valencia, Albatros, 1986.

Torrente Ballester, Gonzalo, El Quijote como juego y otros trabajos críticos, Barcelona, Destino, 1984.

VAReY, John E., Historia de los titeres en España, Madrid, Revista de Occidente, 1957.

Wiltrout, Ann E., «Ginés de Pasamonte: The "Pícaro" and his art», Anales Cervantinos, 17 (1978), pp. 11-17. 


\title{
Resumen
}

En esta investigación se muestran las diversas características del lenguaje (meta)teatral del retablo de maese Pedro en tanto escenificación de una tradición oral a través del lenguaje dramático y mudo de las marionetas y del discurso declamado por el trujamán que las describe. Como consecuencia de esta (re)presentación tenemos, por un lado, la acogida e interpretación de don Quijote como oyente crítico de una lectura dramática de esa tradición de juglares, y por otro, su reacción coherente con su historia de lector aislado y silencioso. La lectura que don Quijote acaba imponiendo es de esta forma la misma lectura muda que le llevó a su locura o enfermedad. El caballero exterioriza además con su actitud el enfrentamiento que durante toda la obra se presenta entre el romance y los libros de caballerías por un lado, y las nuevas formas literarias que venían a suplantarles, destacando entre estos la supremacía del teatro de la nueva comedia y lo que se conocerá muchos años después como novela.

Palabras clave: Maese Pedro. Don Quijote. Cervantes. Oralidad. Metadrama.

Title: Where the one who reads it will see it and the one who listens to it being read will hear it: on the metatheatralical language of Maese Pedro's marionettes

\begin{abstract}
This investigation points out the various characteristics of the (meta)theatrical language of Maese Pedro's retablo, both in the staging of an oral tradition in the mute language of marionettes and in the discourse of the interpreter who describes them. This (re)presentation reveals, on the one hand, don Quixote's interpretation of this performance in the minstrel tradition as a critical listener and, on the other, his reaction as an isolated and silent reader. The reading that don Quixote finally imposes is thus the same mute reading that drove him to madness. His behavior externalizes the confrontation between knightly romances and the new literary forms that were to replace them, highlighting the supremacy of new comedic theater and what would be considered years later as the novel.
\end{abstract}

Key words: Maese Pedro. Don Quijote. Cervantes. Orality. Metadrama. 